АТАНОВ Николай Иванович - доктор экономических наук, профессор; ведущий научный сотрудник Бурятского государственного университета (670000, Россия, Республика Бурятия, г. Улан-Удэ, ул. Смолина, 24a; ni.atanov@yandex.ru)

ПОТАПОВ Леонид Васильевич - доктор экономических наук, профессор; ведущий научный сотрудник Бурятского научного иентра СО РАН (670047, Россия, Республика Бурятия, г. Улан-Удэ, ул. Сахьяновой, 8 (президент Республики Бурятия в 1994-2007 гг.)

\title{
СОПРЯГАЕМОСТЬ «НОВОЙ НОРМАЛЬНОСТИ» КИТАЯ И СТРАТЕГИЧЕСКОГО ПЛАНИРОВАНИЯ РОССИИ
}

Аннотация. На основе сравнительного анализа стратегических документов о «новой норме» (Китай) и "О стратегическом планировании в Российской Федерации" (Россия) авторы устанавливают их принципиальные сходства и различия, обосновывают причины смещения по времени сроков реализации закона о стратегическом планировании. В качестве основной причины называется профессиональная неготовность субъектов и объектов к переходу на новый уровень планирования. Авторы предлагают создать в регионах России научно-образовательные центры поствузовского обучения руководителей и специалистов из сферы бизнеса, государственного и муниципального управления, организовать массовую просветительско-воспитательную работу с населением.

Ключевые слова: стратегия, новая нормальность, устойчивое развитие, человеческий капитал, "зеленая» экономика, обучение, просветительская работа

Э похальным нововведением в оборот мировой политической, научной и прикладной лексики второго десятилетия XXI в. стал термин «новая нормальность». Озвучил его впервые председатель КНР Си Цзиньпин в мае 2014 г. в провинции Хэнань в ходе инспекционной поездки. Смысл «новой нормы» (синь чантай) Китая заключен в двух обоснованиях.

1. Завершается этап высокоскоростного темпа развития, во имя которого нарушались пропорции в экономике, приносились в жертву интересы населения и экологии. На смену высоким темпам роста приходит высокое качество экономической структуры, сбалансированность между отраслями и регионами, повышение энергоэффективности и снижение капиталоемкости, сокращение негативного воздействия на окружающую среду. Итог - перевод экономики из высокоскоростного в средне-высокоскоростной режим с «новой нормой» умеренного роста экономики, оптимизацией ее структуры, повышения качества и эффективности.

2. Заканчивается период встраивания Китая в мировые производственные цепочки в роли поставщика дешевой рабочей силы, вложения заработанных денег в финансовые институты, подконтрольные США. Наступает время опоры на достижения отечественной науки и технологий в производстве конкурентоспособных товаров и услуг, создания независимой финансовой системы и обеспечения глобальных торговых и инвестиционных интересов Китая [Суета сует... 1998: 118-122].

Емкая смысловая нагрузка, уложенная всего в два слова, соответствует духу меняющегося Китая, его росту в мировом рейтинге и символизирует вектор перемен во внутренней и внешней политике на основе обновления базовых положений экономической реальности. Можно предположить, что выход из глобальной нестабильности, кризисов, торговых войн и других потрясений страны мирового сообщества будут искать и находить, формулируя свои национальные концепции «новой нормальности». 
В отечественной политико-экономической среде китайская «новая нормальность» также вошла в оборот, но в видоизмененной формулировке - «новая реальность». Но если «новая нормальность» означает некий заданный стандарт, достижение которого требует обновления базовых положений экономической политики, то «новая реальность» лишь констатирует сложившееся положение вещей. Такое различие исключает адекватность и транспарентность двух терминов. Между тем стагнация в экономике, все больше вбирающая в себя признаки советской экономики второй половины 80-х гг. XX в., требует оперативного вмешательства не столько в духе ускорения, перестройки и гласности в терминах существующей модели экономики, сколько именно в плане ее обновления. Таким решением является переход на систему стратегического управления, закрепленный законом «О стратегическом планировании в Российской Федерации» 1 .

Безусловно, китайская «новая нормальность» - из категории стратегических подходов к обновлению устаревающей модели национальной экономики и к будущей роли Китая в глобальной экономике. Подкреплением и дополнением к доктрине «новой нормальности» стала концепция «Один пояс - один путь», имеющая своей целью создание Евразийского общего рынка с помощью проектов Великого шелкового пути и Морского шелкового пути XXI в.

Отечественный подход к модернизации через законодательный акт не менее фундаментален, чем китайская инновация, более демократичен и предусматривает закладку «новой нормальности» в трехуровневых стратегиях социальноэкономического развития: страны, регионов, муниципалитетов, позволяющих максимально учитывать местные условия, особенности и возможности. Одномоментность выхода китайского и российского управленческих новшеств является знаковым с точки зрения общности проблем, целей и задач в условиях не снижающейся глобальной нестабильности и стремления к совместному взаимовыгодному сотрудничеству как в целях развития национальных экономик, так и для совместного реагирования на возникающие глобальные вызовы.

Различия двух подходов наблюдаются лишь в скорости исполнения принятых решений. Если принципиальные положения, составные элементы и механизмы «новой нормы» Китая к моменту официального озвучивания уже были проработаны и с 2014 г. запущены в реализацию, то новый для российской управленческой практики документ, натолкнувшись на отечественные «рифы быта», стал терять скорость и «плавучесть». Точный и критичный анализ исполнения закона о стратегическом планировании с разных углов зрения, на наш взгляд, дал В.А. Штыров: как производственник с солидным стажем, как руководитель субъекта РФ и как сенатор Совета Федерации [Штыров 2018].

Между тем регионы с задержкой в 2 года готовят субъектные стратегии со смещением периода действия с 2017-2030 гг. на 2019-2035 гг. И так же, как федеральный центр передал лидерство в подготовке документа регионам, последние аналогично поступили по отношению к муниципальным образованиям. В итоге национальная стратегия развития строится со своего основания. Если к данному демократическому подходу отнестись как к управленческому нововведению, то о результатах можно будет судить по итогам защиты позиций нижестоящих стратегий в иерархии перед вышестоящими в условиях жестких лимитов государственного финансирования.

Некоторые обобщения можно сделать исходя из хронологии подготовки документа. Так, в Республике Бурятия к нему приступили в начале 2016 г.

1 Федеральный закон от 28.06.2014 № 272-Ф3 «О стратегическом планировании в Российской Федерации». Доступ: http://base.garant.ru/70684666/ (проверено 17.01.2019). 
Проект проходит третью интеграцию. Главную трудность создает новизна темы и отсутствие опыта. Инерция стереотипа подготовки программ довлеет над разработчиками, а для стратегического охвата, для «прыжка» на уровень «новой нормы» нужна соответствующая подготовка и адекватная среда. К сожалению, в отечественной системе профессионального образования нет специалитета по подготовке стратегических управленцев. Даже в научной среде ученые, владеющие методологией стратегирования, - штучный товар, что же тогда говорить про управленцев-практиков. Сложность предмета подтверждает и сам текст закона о стратегическом планировании. Усвоение его положений не укладывается в привычную рамку чтения, а требует наличия базовой профессиональной подготовки, углубленного изучения с карандашом с многократным подходом.

Эти «ловушки» авторам закона следовало бы знать и проявить стратегический подход и к вопросу усвоения основ стратегического планирования, например подготовить и выпустить практическое пособие и методические рекомендации, учебную программу и сетку часов для обучения пользователей, прежде всего руководителей и специалистов в органах государственной власти и местного самоуправления. Но перед этим следовало бы обучить самих будущих учителей, обратив взор на успешную отечественную историю ускоренной ликвидации безграмотности населения «от Москвы до самых до окраин, с южных гор до северных морей». Ясно, что владение стратегическим мышлением и действиями - достоинство эксклюзивное и уникальное. Поэтому в мировой истории имена стратегов единичны. Строгое следование определению понятия «стратегия» диктует умение выйти за пределы текущих дел, заглянуть за горизонт обыденности и найти единственно правильный «угол атаки» (по В. Квинту) на решаемые проблемы [Квинт 2012: 353].

В отличие от программ, в которых проекты обычно субординируются по приоритетам, определяются размеры и источники ресурсов, обосновываются ожидаемые эффекты и т.д., стратегия (по существу) представляет сверхзадачу, а если строже, - то «гимн в прозе», призывающий к свершению великих дел. И этим искусством нельзя овладеть только при помощи обучения. Но владение методологией стратегирования, методикой стратегического планирования является критичным современную эпоху 4-й научно-технической революции. При этом следует дифференцировать стратегию выбора решения и стратегию подбора механизмов и методов его выполнения.

Стратегическим считается выбор из генеральной совокупности той единственной проблемы, решение которой откроет шлюзы для последовательного выполнения следующих по приоритету задач. Такой проблемой, общей для всех континентов и регионов мира, стран и местных сообществ, являются переход на принципы устойчивого развития (sustainable development).

Актуальна эта проблема и для Республики Бурятия, являющейся водосборной зоной озера Байкал - участка мирового природного наследия.

На саммите «Рио+20» (20-22 июня 2012 г., г. Рио-де-Жанейро) вновь обсуждались проблемы устойчивого развития и искоренения бедности, были выработаны методы и меры их решения 1 . Сама повестка, безусловно, - из категории «новой нормы». Однако до сих пор многие представители управленческой среды отождествляют устойчивое развитие с непрерывным экономическим ростом, хотя устойчивость характеризуется сбалансированностью и пропорциональностью развития всех секторов жизнедеятельности нынешнего поколения людей в гармонии с биосферой, экосферой с таким расчетом, чтобы не лишать

1 Конференция ООН по устойчивому развитию РИО+20. Доступ: https://ria.ru/ eco/20120623/679787921.html 
возможности будущие поколения удовлетворять свои потребности. Причина незнания - в пробелах обучения.

Стратегией подбора механизмов и методов перехода на устойчивое развитие является решительный перевод экономики с опоры на «физическую силу» природных ресурсов на «мягкую, умную силу» знаний, замещение «коричневой» - ресурсопожирающей и экологически пагубной экономики «зеленой» - информационной и цифровой экономикой. Начинать следует с «озеленения» и «цифровизации» сознания на основе обучения не только элит, но всего народонаселения.

Судьбоносным фактором подъема экономики является развитие предпринимательства в регионах. Поэтому «новой нормой» Стратегии должен быть быстрый рост предпринимательской среды: с 6-8\% трудоспособного населения, которые заняты предпринимательской деятельностью в Бурятии в настоящее время, ее численность нужно довести до 35-40\% в 2035 г. Одних призывов и государственных преференций будет недостаточно, чтобы справиться с этой задачей. Просветительская работа с населением, создание экспресс-курсов при бизнес-инкубаторах, при администрациях муниципальных районов позволит решить первичный слой проблемы. Долгосрочный стратегический успех в воспитании и привитии предпринимательского духа и навыков может обеспечить перевод общеобразовательных школ на практикоориентированное обучение, политехнизацию школ, чтобы дети параллельно с изучением законов физики, математики, биологии, химии и т.д. осваивали методику их переложения в практическое русло, создавая новые и добавленные стоимости, овладевали практикой коммерции и маркетинга и реально осязали результаты своего труда. Для этого в первую очередь нужно убрать из федерального закона об образовании вредоносную норму, исключающую привлечение школьников к труду. Видимо, разработчикам закона была неведома аксиома, что труд создал человека. Только привитие с детских лет трудовых и предпринимательских навыков способно сформировать новую генерацию рыночно ориентированного и предпринимательски нацеленного поколения россиян.

Заметим, что выход на мировую лидерскую позицию советская образовательная система обязана именам Макаренко, Сухомлинского, Ушинского и др., а также созданной мощной научно-педагогической базе.

По всей стране была создана сеть научно-технических обществ, центров научно-технической информации (ЦНТИ), на предприятиях действовали общества изобретателей и рационализаторов. Всесоюзное общество «Знание» вело просветительскую работу в трудовых коллективах и среди населения, в университетах марксизма-ленинизма без отрыва от основной деятельности обучались руководители и специалисты. Практически все слои общества были охвачены обучением и повышением квалификации. На наш взгляд, непростительно дорого чураться собственного отечественного положительного опыта. Нужно его возрождать, изменив фокус с идеологической плоскости на практическую.

Знакомство с зарубежной программно-проектной практикой показывает, что во всех изученных авторами страновых материалах, в проектах предусмотрена отдельная статья расходов на обучение персонала, а в отечественных программах и проектах - лишь фрагментарно [Атанов, Семенов 2016].

Послевузовским обучением по финансово-экономической и управленческой специализации занимается Российская академия народного хозяйства и государственной службы (РАНХиГС). Однако для масштабов России интеллектуального капитала одного учреждения явно недостаточно. Даже выборочное и дискретное направление на курсы повышения квалификации руководителей и специалистов из регионов или приглашение в регионы специалистов РАНХиГС 
для проведения экспресс-курсов накладно для бюджета, а поэтому ограниченно. Поэтому регионом нужна система непрерывного обучения на местах.

Казалось бы, этим направлением повышения квалификации и переподготовки кадров должны заниматься вузы в регионе. Такая работа ведется, но только по отдельным заказам. А нужно системное непрерывное и массовое обучение кадров по самым разным сферам деятельности с серьезной методологической и программной базой. Самостоятельно осилить эту задачу и работу без партнерства с органами власти и сообществом промышленников и предпринимателей вузы в одиночку не в состоянии, т.к. на протяжении последних 7 лет перманентно вынуждены заниматься оптимизацией, но не качества образования и науки, а затрат: текущих и капитальных. В такой ситуации творческая энергия коллективов вытесняется отрицательной энергией депрессии. Продолжение тренда имеет одну перспективу - пространственную оптимизацию высшей школы России с известными последствиями.

Наращивание качества человеческого капитала в регионах через систему дополнительного обучения не имеет альтернативы. Но и обучение имеет свой предел возможностей, за которым просматривается элементарный дефицит человеческого потенциала.

Для восточных регионов России при формировании стратегий социальноэкономического развития дамокловым мечом выступает ухудшающаяся демографическая ситуация. Даже самые привлекательные слагаемые «новой нормы» в стратегических целевых установках, имеющих высокую норму прибыли, в ряде случаев отодвигаются по срокам на последующие периоды ввиду проблемы с трудообеспечением. Несмотря на многолетнюю неубывающую динамику исхода народонаселения, проблема миграции не находит системного решения ввиду недостаточности полномочий и ресурсов у региональных органов власти. Между тем «невидимая рука рынка» продолжает свое дело, оголяя без того разреженное экономическое пространство.

Территории провалов рыночных регуляторов давно нуждаются в перезагрузке институтов и механизмов управления на принципы государственного дирижирования. Стратегическим решением могло бы стать заимствование реформаторской «новой нормы» Дэн Сяопина о приживаемости в одной стране двух систем (в связи с переходом Гонконга под юрисдикцию Китая из-под английского протектората). Как видим, за 20 лет дуализм в государственном устройстве прижился: коммунистический режим Китая не рухнул, и Гонконг продолжает оставаться одним из мировых деловых и финансовых центров. Но для заимствования китайского опыта необходима глубочайшая и всесторонняя проработка вопроса политологами, социологами, демографами, экономистами, финансистами, экологами, географами, этнографами. При этом следует учитывать дихотомию проблемных зон у Китая и России: трудоизбыточность и ресурсодефицитность - на одном полюсе, трудодефицитность и ресурсодостаточность - на другом. Многоаспектность и многослойность темы не укладывается в регламент и рамки статьи.

Можно в этом же духе продолжать нанизывать проблемы стратегического уровня на нить логической схемы изложения материала, но основной посыл ясен.

1. По существу «новая норма» Си Цзиньпина является новой стратегией Китая, обновившей реформы, начатые Дэн Сяопином. Цель ясна и задачи определены -к 100-летию Коммунистической партии Китая достичь средней зажиточности населения (сяокан).

2. Пробуксовка с исполнением федерального закона «О стратегическом планировании» по всей иерархической вертикали есть следствие неготовности к 
восприятию его принципиальных положений со стороны субъектов и объектов управления. В свою очередь, причина неготовности/отторжения - в недостаточности профессиональной квалификации, т.е. грамотности.

3. Подготовленный проект Стратегии социально-экономического развития республики Бурятия - 2035 нельзя признать полноценной стратегией. Скорее документ представляет некую комбинацию госпрограммы и стратегии. «На высокую башню можно подняться лишь по винтовой лестнице», - утверждал Френсис Бэкон. Он же заметил, что «нововведения подобны новорожденным: на первых порах они необычайно нехороши собой» [Суета сует... 1998: 11,12].

4. С опорой на отечественный исторический опыт в регионах необходимо возродить научно-образовательные центры для параллельного поствузовского обучения руководителей и специалистов из реального сектора экономики, государственного и муниципального управления, проведения прикладных исследовательских работ. С учетом актуальности вопроса и требований времени оптимальный подход видится в организованном решении из центра, исходя из российской ментальности, склонной к действовиям «во исполнение». РАНХиГС возглавил бы научно-методическое и координационное руководство.

5. Не меньшим, а большим потенциалом полезности в деле прогресса общества обладает просветительско-воспитательная работа с народонаселением путем восстановления институтов просвещенческо-пропагандистской работы в регионах. Стратегическое видение и управление, стратегические подходы к действиям имманентно присущи только грамотному менеджменту и просвещенному обществу.

Высказывание О. фон Бисмарка о том, что «победу в войнах одерживает учитель», в современной действительности относится и к экономическим победам.

\section{Список литературы}

Атанов Н.И., Семенов Ф.В. 2016. Развитие отечественной школы регионального стратегического планирования с использованием мирового опыта: монография. Улан-Удэ: Изд-во Бурятского государственного университета. 160 с.

Квинт В. 2012. Стратегическое управление и экономика на глобальном формирующемся рынке. М.: Бизнес-Атлас. 627 с.

Суета сует: 500 лет английского афоризма (пер. с англ. А. Ливерганта). 1998. М.: ТЕРРА-Книжный клуб. 300 с.

Штыров В.А. 2018. Зачем России Госплан? - Аргументы и факты. № 16. 18.04.

ATANOV Nikolai Ivanovich, Dr.Sci. (Econ.), Professor; Leading Researcher, Buryat State University (24a Smolina St, Ulan-Ude, Republic of Buryatia, Russia, 670000; ni.atanov@yandex.ru)

POTAPOV Leonid Vasil'evich, Dr.Sci. (Econ.), Professor; Leading Researcher, Buryat Scientific Center, SB RAS (8 Sakhyanovoj St, Ulan-Ude, Republic of Buryatia, Russia, 670047) (President of the Republic of Buryatia in 19942007)

\section{MATCHING THE «NEW NORMALITY» OF CHINA AND RUSSIA'S STRATEGIC PLANNING}

Abstract. On the base of comparative analysis of such strategic courses as «new normality» (China) and "On strategic planning in the Russian Federation" (Russia) the article establishes their fundamental similarities and differences. The authors substantiate reasons for the time shifting of implementation of the law on strategic planning. The main one is the professional unavailability of subjects and objects to the transition to a new level of planning. The authors propose creating in the regions 
of Russia scientific and educational centers for post-university training of managers and specialists from the sphere of business, state and municipal management, and organization of educational work among the population.

Keywords: strategy, new normality, sustainable development, human capital, green, digital economy, training, educational work

АЛИГАДЖИЕВА Мадина Алиевна - соискатель Российской академии народного хозяйства и государственной службы при Президенте РФ (119571, Россия, г. Москва, пр-кт Вернадского, 82, стр. 1; aligad_m@mail.ru)

\section{КЛАНОВОЕ И ЭТНИЧЕСКОЕ РАЗМЫВАНИЕ ПОЛИТИЧЕСКОЙ ЭЛИТЫ ДАГЕСТАНА}

Аннотация. Учитывая внутренние и внешние проблемы, с которыми столкнулась современная Россия, безусловно, возрастает и роль национально ориентированной элиты, главными трендами для которой должны стать созидание, сохранение и стабильность страны. Цель статьи - выявить клановое размывание политической элиты Республики Дагестан. Работа подготовлена на материалах социологических исследований, проведенных автором методом анкетирования. Полученные результаты целесообразно применять в рамках государственной политики РФ в сфере национальной политики и межконфессиональных отношений для более полной информированности органов государственной и муниципальной власти, общественных организаций и движений.

Ключевые слова: политическая элита, кланы, размывание, исследования, Дагестан

$\mathrm{K}$ лановая структура правления, присутствующая во многих регионах страны, лишает национальную элиту возможности созидательной и стабильной деятельности в интересах государства и для его пользы. Многочисленные попытки искоренить ее в Дагестане не увенчались успехом: она всегда возрождалась вновь. Большие надежды в этой области возлагались на Р.Г. Абдулатипова, от которого, учитывая отсутствие у него приверженности к каким-либо кланам, ожидали размывания этнической клановости в республике.

Исследования, которые проводились в 2013 г., показали, что, без сомнения, клановый принцип превалирует над всеми остальными критериями вхождения в политическую элиту. Так, на вопрос исследования, проведенного в февралемарте 2013 г. в Республике Дагестан: «Какие основные принципы вхождения в политическую элиту характерны для Республики Дагестан?» - наибольшее число респондентов отметили клановый принцип (76,9\%), 19,2\% отметили семейные и родственные отношения, и только 15,5\% выбрали вариант ответа «путем собственных усилий» [Алигаджиева 2014]. Причем надо отметить, что на Северном Кавказе процессы клановости в формировании политических элит гораздо сильнее выражены, чем на Южном ${ }^{1}$.

Аналогичное исследование было проведено в 2015 г. На вопрос: «Кому, на ваш взгляд, реально принадлежит нынешняя власть в республике?» - были получены следующие ответы: первому руководителю республики - 18,60\%, различным кланам - 15,80\%, коррумпированной части аппарата $-14,10 \%$, материально обеспеченным людям, предпринимателям, коммерсантам $-7,90 \%$,

1 Бодио Т. Политическое лидерство и политические элиты Кавказа. Доступ: https://bredikhinav. livejournal.com/64119.html (проверено 11.12 2018). 